\title{
Physicochemical Quality Parameters at the Reception of the Honey Packaging Process: Influence of Type of Honey, Year of Harvest, and Beekeeper
}

\author{
Marisol Juan-Borrás, ${ }^{1}$ Eva Domenech, ${ }^{1}$ Andrea Conchado, ${ }^{2}$ and Isabel Escriche ${ }^{1}$ \\ ${ }^{1}$ Instituto Universitario de Ingeniería de Alimentos para el Desarrollo (IUIAD), Departamento de Tecnología de Alimentos (DTA), \\ Universitat Politecnica de Valencia (UPV), Camino de Vera, s/n, 46022 Valencia, Spain \\ ${ }^{2}$ Departamento de Estadística e Investigación Operativa Aplicadas y Calidad, Centro de Gestión de la Calidad y del Cambio, \\ Universitat Politecnica de Valencia (UPV), Camino de Vera, s/n, 46022 Valencia, Spain
}

Correspondence should be addressed to Isabel Escriche; iescrich@tal.upv.es

Received 25 November 2014; Accepted 7 April 2015

Academic Editor: Dimitris P. Makris

Copyright (C) 2015 Marisol Juan-Borrás et al. This is an open access article distributed under the Creative Commons Attribution License, which permits unrestricted use, distribution, and reproduction in any medium, provided the original work is properly cited.

\begin{abstract}
The aim of this paper was to evaluate the influence of the type of honey, year of collection, and the beekeeper on the main physicochemical quality parameters (hydroxymethylfurfural "HMF", moisture, and colour), measured on reception of the raw honey. 1593 samples (11 types of honey categorized by means of pollinic analysis), provided by 98 beekeepers, from 2009 to 2013 , were analyzed. Colour was the parameter most affected by the type of honey and year, whereas HMF was the least affected in both cases. The clearest honeys were found to have the greatest moisture (orange, rosemary, and lemon) and the darkest had the least moisture (lavender stoechas, eucalyptus, sunflower, honeydew and retama). Lavender, polyfloral, and thyme had intermediate values of these parameters. For moisture, most samples were in accordance with international requirements (less than $20 \mathrm{~g} / 100 \mathrm{~g}$ ). All values were below the required limit for $\operatorname{HMF}(40 \mathrm{mg} / \mathrm{kg})$, although a few of them were abnormally high as they were raw honeys (i.e., $2 \%$ of the samples had values higher than $20 \mathrm{mg} / \mathrm{kg}$ ). The fact that all the inadequate samples came from specific beekeepers highlights the importance of their role, suggesting that training in good practices is the key to guarantee honey quality before it reaches the industry.
\end{abstract}

\section{Introduction}

Food products have to satisfy numerous quality criteria before commercialization, especially in industrialized countries, where there is a need for high quality products with well-defined characteristics. Honey is not an exception and must be delivered to the consumer with its essential composition and quality minimally altered with respect to freshly harvested honey [1]. There are international and sometimes local regulations that specify honey quality $[2,3]$. Therefore, on receiving batches of raw honey, the packaging industry has to carry out a wide range of analyses, such as quantification of pollen and physicochemical parameters (hydroxymethylfurfural "HMF," moisture, and colour, among others). There are two main reasons for this: (1) to facilitate the classification of honeys according to their botanical origin (considering the pollinic percentage and colour) and (2) to meet the legislated mandatory requirements during commercialization (e.g., HMF content less than $40 \mathrm{mg} / \mathrm{kg}$ or moisture content less than $20 \mathrm{~g} / 100 \mathrm{~g}$ ) [2].

Honey classified as unifloral always has a higher commercial value than polyfloral. For this reason, the industry realizes this task prior to packaging, when according to information provided by the beekeeper there is a reasonable probability that a honey can be classified as unifloral. The identification and quantification of the percentage of pollen by microscopic examination are used to authenticate the botanical origin of honey [4-6]. The colour of honey is directly related to the botanical source of the nectar and therefore can help in the classification of unifloral honeys. In addition, this parameter 
has commercial value as it is used as a criterion of acceptance or rejection by the consumers; however, it is only regulated by some Quality Marks [3].

HMF is the most consistent indicator of honey freshness as it is practically absent in freshly harvested honey. However, it increases during handling, extraction, conditioning, or storage operations and also as a consequence of the liquefaction and pasteurization carried out to improve manageability and destroy the crystallization nuclei [7]. Honey packaging plants must be very demanding about the HMF content of raw honey, as they are obliged by law to comply with the requirement established for this parameter during the bestbefore-date printed on the label. The moisture content of honey depends on the season in which it is harvested, the climatic conditions, and the good practices carried out by the beekeepers [8]. This parameter has a decisive influence on viscosity, flavor, and palatability but overall on crystallization and fermentation [9]. These two alterations modify the appearance and therefore contribute to customer rejection, consequently causing losses to the industry.

The honey packaging industry realises the importance of legal compliance but also the necessity of providing consumers with consistent quality. When the process is controlled carefully, the key to a quality end product lies in the good quality of the raw material. Knowledge about the origin of the variability of the critical parameters of physicochemical quality is essential to take measures to improve the quality of the raw honey. Consequently, the probability that the commercialized honey does not meet the required specifications will be reduced. Therefore, the objective of this paper was to evaluate the influence of the type of honey, year of collection, and the beekeeper's role on the main physicochemical quality parameters analysed (HMF, moisture, and colour) on reception in packaging companies.

\section{Material and Methods}

2.1. Sampling Collection. A total of 1593 samples of raw honey, collected over five years (from 2009 to 2013) in the routine checks that take place on reception of raw honey, were analysed. These samples came from four commercial organizations (provided by 98 beekeepers) located in the Valencian region (Spain). The samples represented the most common varieties available in Spain: 231 (14.5\%) were orange blossom (Citrus sp.), 111 (7\%) lemon blossom (Citrus limon sp.), 216 (13.6\%) rosemary (Rosmarinus officinalis), 135 (8.5\%) sunflower (Helianthus annuus), 34 (2.1\%) thyme (Thymus spp.), 27 (1.7\%) lavender (Lavandula spp.), 14 (0.9\%) lavander stoechas (Lavandula stoechas), 26 (1.6\%) retama (Lygos sphaerocarpa), 76 (4.8\%) eucalyptus (Eucalyptus spp.), 117 (7.3\%) honeydew honey, and 605 (38\%) polyfloral.

The botanical categorization of all the batches was carried out by means of pollinic analysis.

\subsection{Analytical Determinations}

2.2.1. Melissopalynological Analysis. The percentage of pollen was obtained for each sample following the recommendations of the International Commission for Bee Botany [4].
Microscopic examination was carried out at the magnification that was most suitable for identifying the various elements in the sediment (400 to $1000 \mathrm{x}$ ). A light microscope (Zeiss Axio Imager, Göttingen, Germany) at a magnification power of $\times 400$ with DpxView LE image analysis software attached to a DeltaPix digital camera was used.

2.2.2. Physicochemical and Colour Analysis. Hydroxymethylfurfural content "HMF" (White method) and moisture content were analyzed in accordance with the Harmonized Methods of the European Honey Commission [10]. Colour was determined using a millimetre Pfund scale C 221 Honey Color Analyzer (Hanna Instruments). All tests were performed in triplicate.

2.3. Statistical Analyses. A multifactor analysis of variance (ANOVA) (using Statgraphics Centurion for Windows) was applied to study the influence of the type of honey and the year of harvesting on the HMF, moisture, and colour. LSD (least significant difference) contrast with level of significance $\alpha=5 \%$ was used to analyse the differences between means. A multiple correspondence analysis was applied using the statistical software SPAD (version 6.0) to group types of honey based on the quality parameters analysed and also to better understand the relationship between the parameters and the honeys.

\section{Results and Discussion}

3.1. Pollinic Analysis. The first step in this study was to carry out the botanical categorization of all the batches by means of pollinic analysis. As an example, Figure 1 shows several pictures corresponding to the predominant pollen present in each type of unifloral honey. Next to each botanical name, the minimum percentage of pollen required to classify a honey as belonging to a specific botanical genus considered in the present work is shown. These values represent the minimums commonly used in the industry and recommended by different authors and Quality Marks [3, 4, 8, 11-14]. Honey was classified as honeydew if the ratio of honeydew elements to that of pollen grains exceeded 3 and the conductivity was higher than $0.8 \mathrm{mS} / \mathrm{cm}$ [2]. Finally, honey was classified as polyfloral if it did not contain sufficient pollen from a specific botanical species.

\subsection{Influence of Type of Honey and Year of Harvest on the} Physicochemical Parameters. Table 1 shows the descriptive statistics (mean and standard deviation) of HMF, moisture, and colour parameters analysed considering the type of honey and year of harvest. In addition, this table shows the ANOVA results ( $F$-ratio and significant differences) obtained for these two factors. The interaction between both factors was not significant. Considering that the higher the F-ratio, the greater the effect that a factor has on a variable, colour was the parameter most affected by the factors "type of honey" and "year," whereas HMF was the least affected in both cases, as was expected.

A Kolmogorov-Smirnov test (data not shown) demonstrated that data related to moisture and colour were normally 


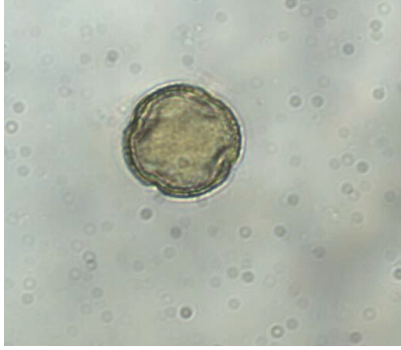

Citrus sinensis (>10\% pollen)

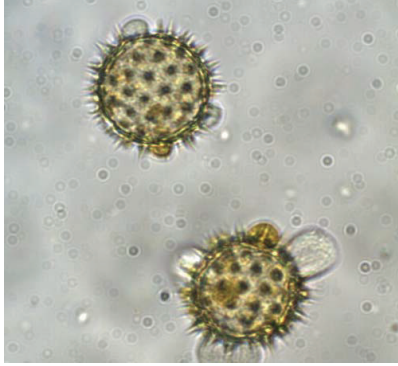

Helianthus annuus ( $>45 \%$ pollen)

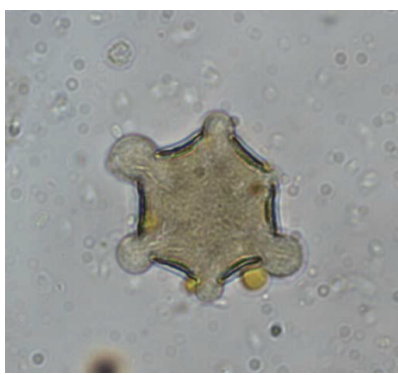

Lavandula stoechas ( $>12 \%$ pollen)

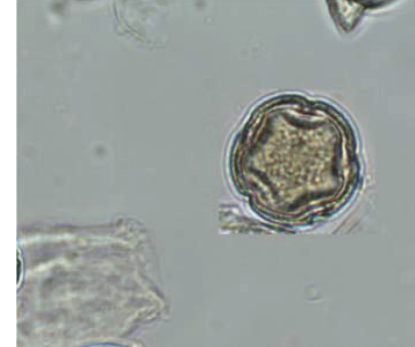

Citrus limon ( $>10 \%$ pollen)

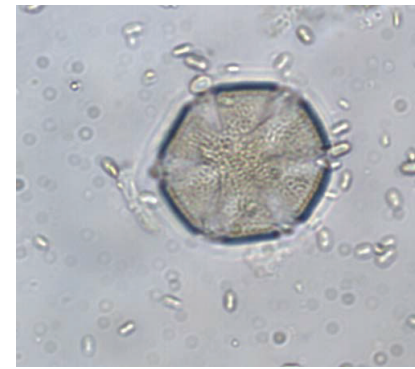

Thymus sp. (>12\% pollen)

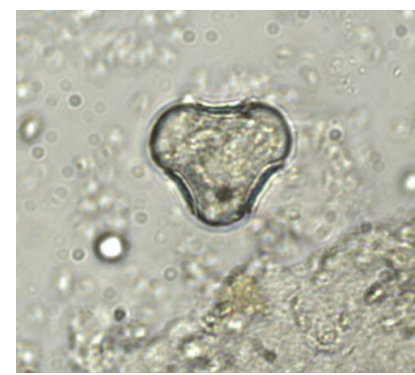

Lygos sphaerocarpa (>35\% pollen)

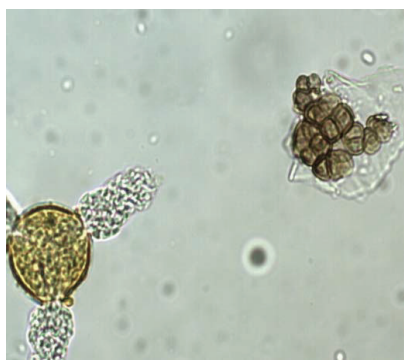

Honeydew

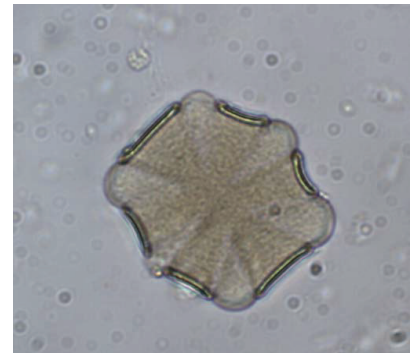

Rosmarinus officinalis ( $>10 \%$ pollen)

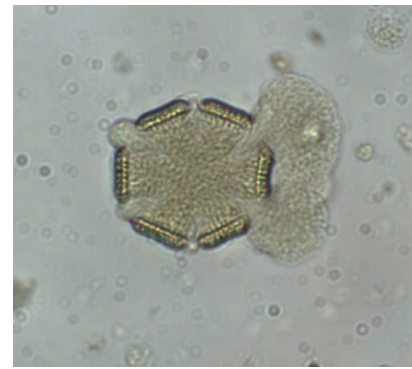

Lavandula latifolia (>12\% pollen)

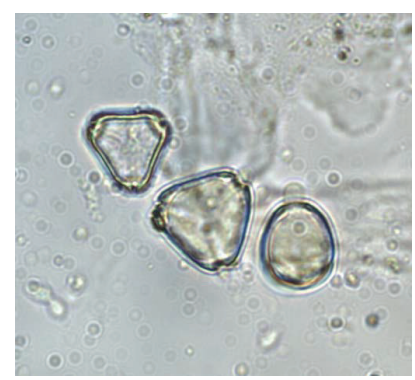

Eucaliptus sp. (>70\% pollen)

FIGURE 1: Pictures corresponding to the predominant pollen present in each type of unifloral honey and the minimum percentage of pollen required to classify a honey as belonging to a specific botanical genus considered in the present work.

distributed; however, the HMF data were not normally distributed as their descriptive statistics showed a strong positive skew (skewness coefficient $=2.7$ ) and a high positive kurtosis (kurtosis coefficient $=10.1$ ).

HMF ranged between a minimum value of $<0.5 \mathrm{mg} / \mathrm{kg}$ (data that are present in all varieties) and a maximum of $37.4 \mathrm{mg} / \mathrm{kg}, 37.9 \mathrm{mg} / \mathrm{kg}$, and $39.8 \mathrm{mg} / \mathrm{kg}$ in sunflower honey, orange blossom honey, and polyfloral honey, respectively. Although all values were below the required limit of $40 \mathrm{mg} / \mathrm{kg}$, it is obvious that some of them would be considered as unacceptable as they were raw honeys. It should be noted that these outlying values are not frequent; in fact only
$2 \%$ of samples had values higher than $20 \mathrm{mg} \mathrm{HMF} / \mathrm{kg}$, and less than $0.5 \%$ of samples had values higher than $30 \mathrm{mg}$ $\mathrm{HMF} / \mathrm{kg}$. In contrast with the type of honeys mentioned before, retama, eucalyptus, lavander stoechas, and lemon honeys had maximum values of 7.4, 9.7, 10.2, and 10.3, respectively.

With respect to the moisture, it can be observed (Table 1) that a high value of this parameter is characteristic of certain types of honey, such as thyme and rosemary, with average values equal or higher than $19.5 \mathrm{~g} / 100 \mathrm{~g}$. Some specific batches of orange blossom, lemon tree, rosemary, sunflower, thyme, lavender, honeydew, and polyfloral honeys also exceeded 
TABLE 1: Descriptive statistics for moisture, colour, and HMF for each variety of honey and year of harvesting. ANOVA results $(F-$ ratio and significant differences) obtained for two factors: type of honey and year of harvest.

\begin{tabular}{|c|c|c|c|c|c|c|c|c|c|c|c|c|}
\hline \multirow{2}{*}{ Type of honey } & \multicolumn{4}{|c|}{$\mathrm{HMF}(\mathrm{mg} / \mathrm{kg})$} & \multicolumn{4}{|c|}{ Moisture (g/100 g) } & \multicolumn{4}{|c|}{ Colour (Pfund scale) } \\
\hline & Mean & $\mathrm{SD}$ & Min & Max & Mean & $\mathrm{SD}$ & Min & Max & Mean & $\mathrm{SD}$ & Min & Max \\
\hline Orange blossom & $4.6^{\mathrm{de}}$ & 6.4 & $<0.5$ & 37.9 & $18.7^{\mathrm{c}}$ & 1.3 & 15.5 & 23.3 & $27^{\mathrm{a}}$ & 17 & 2 & 62 \\
\hline Lemon tree & $2.1^{\mathrm{ab}}$ & 2.3 & $<0.5$ & 10.3 & $18.3^{\mathrm{b}}$ & 1.5 & 15.0 & 21.6 & $26^{\mathrm{a}}$ & 14 & 1 & 69 \\
\hline Rosemary & $3.2^{\mathrm{bc}}$ & 3.2 & $<0.5$ & 27.3 & $19.9^{\mathrm{d}}$ & 2.1 & 15.0 & 25.0 & $25^{\mathrm{a}}$ & 15 & 0 & 50 \\
\hline Sunflower & $3.3^{\mathrm{bc}}$ & 4.3 & $<0.5$ & 37.4 & $16.7^{\mathrm{a}}$ & 1.3 & 14.6 & 21.2 & $70^{\mathrm{d}}$ & 10 & 38 & 72 \\
\hline Thyme & $4.1^{\mathrm{bcd}}$ & 7.2 & $<0.5$ & 35.6 & $19.5^{\mathrm{d}}$ & 1.6 & 16.2 & 22.9 & $66^{\mathrm{cd}}$ & 21 & 18 & 90 \\
\hline Lavender & $6.1^{\mathrm{d}}$ & 6.2 & $<0.5$ & 22.9 & $17.9^{\mathrm{ab}}$ & 2.2 & 15.7 & 25.2 & $48^{\mathrm{b}}$ & 21 & 6 & 91 \\
\hline Lavender stoechas & $3.4^{\text {abcde }}$ & 3.5 & $<0.5$ & 10.2 & $16.5^{\mathrm{a}}$ & 1.0 & 15.2 & 18.1 & $66^{\mathrm{cd}}$ & 13 & 36 & 78 \\
\hline Retama & $1.0^{\mathrm{a}}$ & 1.7 & $<0.5$ & 7.4 & $16.4^{\mathrm{a}}$ & 0.7 & 14.7 & 17.5 & $84^{\mathrm{e}}$ & 10 & 63 & 120 \\
\hline Eucalyptus & $3.8^{\mathrm{cd}}$ & 2.7 & $<0.5$ & 9.7 & $16.6^{\mathrm{a}}$ & 0.8 & 15.1 & 19.8 & $70^{\mathrm{d}}$ & 11 & 35 & 89 \\
\hline Honeydew & $4.5^{\mathrm{de}}$ & 3.1 & $<0.5$ & 27.2 & $16.5^{\mathrm{a}}$ & 1.4 & 13.9 & 22.0 & $90^{\mathrm{e}}$ & 13 & 57 & 127 \\
\hline Polyfloral & $4.5^{\mathrm{cd}}$ & 4.8 & $<0.5$ & 39.8 & $17.7^{\mathrm{ab}}$ & 1.8 & 14.8 & 24.1 & $64^{\mathrm{c}}$ & 19 & 7 & 130 \\
\hline ANOVA $F$-ratio & $4.42^{* * *}$ & & & & $49.0^{* * *}$ & & & & $221^{* * *}$ & & & \\
\hline \multirow{2}{*}{ Year of harvest } & \multicolumn{4}{|c|}{ HMF } & \multicolumn{4}{|c|}{ Moisture } & \multicolumn{4}{|c|}{ Colour } \\
\hline & Mean & SD & Min & Max & Mean & SD & Min & Max & Mean & $\mathrm{SD}$ & Min & Max \\
\hline 2009 & $3.1^{\mathrm{a}}$ & 3.4 & $<0.5$ & 19.4 & $17.1^{\mathrm{a}}$ & 1.5 & 14.8 & 24.0 & $72^{\mathrm{e}}$ & 18 & 13 & 130 \\
\hline 2010 & $5.0^{c}$ & 5.9 & $<0.5$ & 37.9 & $18.0^{\mathrm{bc}}$ & 1.7 & 15.0 & 23.6 & $62^{\mathrm{d}}$ & 24 & 10 & 127 \\
\hline 2011 & $4.0^{\mathrm{b}}$ & 4.8 & $<0.5$ & 37.4 & $18.2^{\mathrm{cd}}$ & 2.0 & 13.9 & 25.0 & $51^{c}$ & 27 & 2 & 125 \\
\hline 2012 & $2.9^{\mathrm{a}}$ & 3.6 & $<0.5$ & 26.8 & $18.4^{\mathrm{d}}$ & 1.9 & 15.5 & 25.2 & $47^{\mathrm{b}}$ & 27 & 3 & 120 \\
\hline 2013 & $4.1^{\mathrm{bc}}$ & 6.2 & $<0.5$ & 39.8 & $17.9^{\mathrm{b}}$ & 1.7 & 14.2 & 22.1 & $40^{\mathrm{a}}$ & 26 & 0 & 110 \\
\hline ANOVA $F$-ratio & $7.14^{* * *}$ & & & & $17.32^{* * *}$ & & & & $55.94^{* * *}$ & & & \\
\hline
\end{tabular}

${ }^{* * *} p<0.001$. For each factor, different letters in each column indicate homogeneous groups (significant differences at $95 \%$ confidence level as obtained by the LSD test).

$20 \mathrm{~g} / 100 \mathrm{~g}$ moisture. On the contrary, this percentage was quite low in some varieties such as lavander stoechas, retama, and eucalyptus. In general, unifloral honeys show some typical differences in water content depending on season and climate [8]. Taking into account the fact that the moisture content of honey has to be lower than $20 \mathrm{~g} / 100 \mathrm{~g}$ [2], the values obtained in this work were not always satisfactory for the honey packaging industry.

With regard to colour, the results shown in this work were as expected for these varieties of honey [15]. A large range of variation between the minimum and maximum was observed. Logically, the greatest difference was detected in polyfloral honey with a range of 7 to $130 \mathrm{~mm}$ Pfund. Some types of honey such as rosemary, lemon, and orange are in general characterized by a light colour which makes them highly valued commercially. However, these honeys were sometimes darker than is commercially desirable, ranging from 0,1 , and $2 \mathrm{~mm}$ to 50,69 , and $62 \mathrm{~mm}$, respectively. The color of these types of honey can sometimes be strongly influenced by the nectar of other flowers that bees do to sip. On the contrary, honeydew honey and retama honey were in general the darkest (among the monovarietal honeys), reaching up to $120 \mathrm{~mm}$ on the Pfund scale. In these types of honey, the dark colour is traditionally a highly valued characteristic. Furthermore, today it is well known that the darker that honey, the higher the nutritional value, due to the high mineral content and the antioxidant activity $[16,17]$.

In relation to colour, although no limits are established by the general regulations [2], specific Quality Marks limit values according to varieties, for example, for citrus and rosemary less than $30 \mathrm{~mm}$ Pfund in Valencian region regulation [3] and less than 30 and $35 \mathrm{~mm}$ Pfund, respectively, in Granada PDO [18]; for lavender stoechas and thyme, values must be above 50 and $55 \mathrm{~mm}$ Pfund, respectively, in Granada PDO.

In order to detect possible grouping of the types of honeys according to the quality parameters evaluated, a multiple correspondence analysis was carried out (Figure 2) [19]. Due to the requirements of the analysis, quality parameters were coded categorically as intervals. The parameter values were moisture (g/100 g) $[<16,16-17,17-18,18-19,19-20,>20]$; colour (Pfund scale) $[<20,20-30,30-40,40-50,50-60,60-70$, $70-80,>80]$; hydroxymethylfurfural $[<0.50,0.51-1.00,1.01-$ $1.50,1.51-2.00,2.01-2.50,2.51-3.50,3.51-5.00,5.01-6.50,6.51-$ $10.00,>10]$. In addition, information about the variety of honey was projected on the biplot in order to link this factor to quality parameter intervals.

The projection of the varieties on the graph showed three clear groups: left (orange blossom, lemon, and rosemary); centre (thyme, lavender, and polyfloral), and right (sunflower, lavander stoechas, retama, eucalyptus, and honeydew). These groups are also related to certain categories of the quality parameters: the clearest honeys with the highest moisture on the left and the darkest ones with the least moisture on the right. The remaining honeys, with intermediate values of these parameters, are located in the central area of the graph.

The second axis distinguishes samples depending on whether values of hydroxymethylfurfural are close to the 
TABLE 2: Influence of the beekeeper on the physicochemical parameters (HMF, moisture, and colour) and different types of honey. ANOVA results ( $F$-ratio and significant differences) for the factor: beekeeper.

\begin{tabular}{|c|c|c|c|c|c|c|c|c|c|}
\hline \multirow[b]{2}{*}{ Type of honey } & \multicolumn{3}{|c|}{$\mathrm{HMF}(\mathrm{mg} / \mathrm{kg})$} & \multicolumn{3}{|c|}{ Moisture (g/100 g) } & \multicolumn{3}{|c|}{ Colour (Pfund scale) } \\
\hline & Mean (SD) & Min-max & $\begin{array}{c}\text { ANOVA } \\
F \text {-ratio }\end{array}$ & Mean (SD) & Min-max & $\begin{array}{c}\text { ANOVA } \\
F \text { ratio }\end{array}$ & Mean (SD) & Min-max & $\begin{array}{c}\text { ANOVA } \\
F \text { ratio }\end{array}$ \\
\hline Orange blossom & $5.5(7.8)$ & $<0.5-37.8$ & $15.3^{* * *}$ & $19(1)$ & $16-23$ & $4.3^{* * *}$ & $26(16)$ & $2-89$ & $5.48^{* * *}$ \\
\hline Lemon tree & $2.2(2.4)$ & $<0.5-10.3$ & $19.2^{* * *}$ & $18(1)$ & $15-22$ & $11.2^{* * *}$ & $27(14)$ & $1-69$ & $2.35^{*}$ \\
\hline Rosemary & $19.9(2.1)$ & $<0.5-27.3$ & $9.3^{* * *}$ & $20(2)$ & $16-25$ & $2.1^{*}$ & $26(16)$ & $0-75$ & $3.09^{* * *}$ \\
\hline Sunflower & $3(5)$ & $0-10$ & $2.06^{*}$ & $17(1)$ & $15-21$ & $16.3^{* * *}$ & $70(9)$ & $43-90$ & $1.88^{*}$ \\
\hline Honeydew & $6(6)$ & $<0.5-27.3$ & $10.18^{* * *}$ & $17(1)$ & $15-22$ & $4.1^{* * *}$ & $90(12)$ & $57-118$ & $15.8^{* * *}$ \\
\hline Polyfloral & $4.5(4.8)$ & $<0.5-39.8$ & $9.08^{* * *}$ & $18(2)$ & $15-24$ & $4.5^{* * *}$ & $64(19)$ & $7-116$ & $3.6^{* * *}$ \\
\hline
\end{tabular}

${ }^{*} p<0.05{ }^{* * *} p<0.001$.

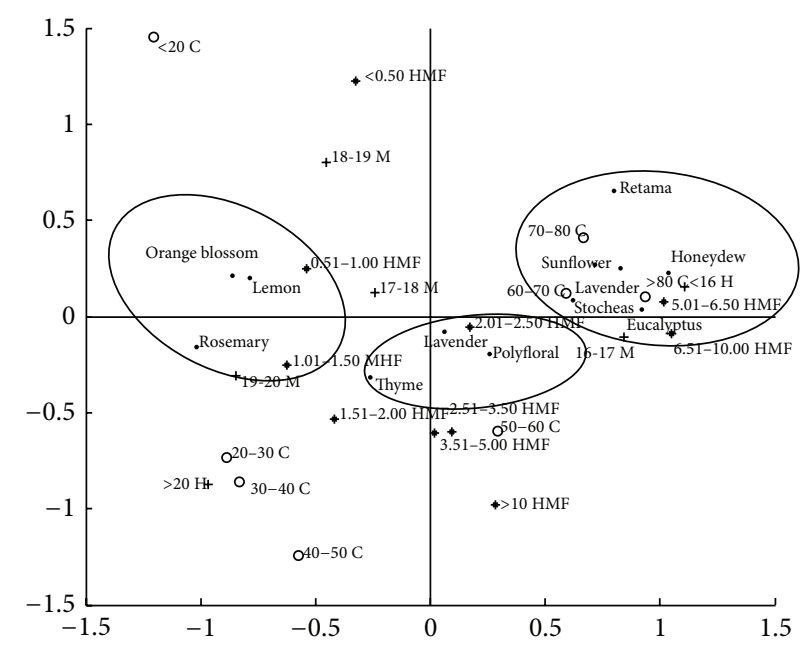

FIGURE 2: Multiple correspondence analyses of the quality parameters coded as intervals with projected varieties of honey. M: moisture; C: colour; HMF: hydroxymethylfurfural.

maximum or the minimum or remain around intermediate values. In this way, minimum values of HMF are located at the top of Figure $2(<0.50 \mathrm{HMF})$, whereas maximum values can be found at the bottom (>10 HMF). In both cases, these categories have a high relative contribution to this second axis, as shown in brackets. The remaining categories of HMF are distributed between these two reference points, but this distribution is not progressive along the axis.

\subsection{Influence of the Beekeeper on the Physicochemical Param-} eters. In order to evaluate the influence of the beekeeper on the physicochemical parameters, the six most abundant honey types analysed in this work were considered (see Section 2.1): orange blossom, lemon blossom, rosemary, sunflower, honeydew, and polyfloral. An ANOVA was carried out for every type of honey and every physicochemical parameter, considering the factor beekeeper (Table 2). For this statistical analysis, beekeepers who contributed less than 10 batches to the study were not considered. It can be observed that the beekeeper has a significant influence on all the parameters evaluated and on all the types of honey studied.

In relation to the quality parameters, HMF and moisture, although only a few values exceeded the recommended limits, these values came from specific types of honey and beekeepers. What is clear is that if some beekeepers can work very well, which is reflected in low values of both parameters, others should be able to also.

Colour differences are more justifiable in comparison to those observed for the parameters mentioned before. That is to say, for the same honey type, the accompanying flora has a large influence on the variations in colour. However, it is important to note that beekeepers also have an influence on this parameter since they are responsible for the mix of the types of honey when cutting the honey from the honeycomb.

Due to the fact that beekeepers have a key role in honey quality parameters, it is important to monitor their handling practices, although this is not always possible if they operate in distant countries.

\section{Conclusion}

Consideration of the botanical origin of the eleven types of honey analysed permitted grouping according to the physicochemical parameters. The clearest honeys were at the same time the ones with the highest moisture while the darkest honeys were found to have the lowest moisture levels. Colour 
was the parameter most affected by the type of honey and year of harvesting, whereas HMF was the least affected in both cases. There were some unacceptable outliers from specific beekeepers which exceeded the permitted values for moisture and the recommended values of HMF. This indicates the important role that the beekeeper has in attaining raw honey with the correct physicochemical parameters, and even the characteristic colour which the market requires. When the process is controlled carefully, the key to the quality of the end product lies in the good quality of the raw material. Therefore, adequate training in good beekeeping practices is vital to obtain the product that the consumer expects and legislation requires.

\section{Conflict of Interests}

The authors declare that they have not conflict of interests.

\section{References}

[1] Codex Alimentarius, Revised Codex Standard for Honey. Codex Stan 12-1981, vol. 1-2, Codex Alimentarius Commission, 2001.

[2] European Union, "Council Directive 2001/110 relating to honey," Official Journal of the European Communities, L10, pp. 47-52, 2002.

[3] "Reglamento de la Marca de Calidad CV para miel de azahar y romero in Diario Oficial de la Generalitat Valenciana," DOGV 4167, Area de publicaciones de la Presidencia de la Generalitat Publishing, Valencia, Spain, 2002.

[4] W. Von Der Ohe, L. Persano Oddo, M. L. Piana, M. Morlot, and P. Martin, "Harmonized methods of melissopalynology," Apidologie, vol. 35, supplement 1, pp. S18-S25, 2004.

[5] I. Escriche, M. Kadar, E. Domenech, and L. Gil-Sánchez, "A potentiometric electronic tongue for the discrimination of honey according to the botanical origin. Comparison with traditional methodologies: physicochemical parameters and volatile profile," Journal of Food Engineering, vol. 109, no. 3, pp. 449-456, 2012.

[6] S. Panseri, A. Manzo, L. M. Chiesa, and A. Giorgi, "Melissopalynological and volatile compounds analysis of buckwheat honey from different geographical origins and their role in botanical determination," Journal of Chemistry, vol. 2013, Article ID 904202, 11 pages, 2013.

[7] M. Visquert, M. Vargas, and I. Escriche, "Effect of postharvest storage conditions on the colour and freshness parameters of raw honey," International Journal of Food Science and Technology, vol. 49, no. 1, pp. 181-187, 2014.

[8] L. Persano-Oddo and R. Piro, "Main European unifloral honeys: descriptive sheets," Apidologie, vol. 35, supplement 1, pp. S38S81, 2004

[9] I. Turhana, N. Tetika, M. Karhana, F. Gurelb, and H. R. Tavukcuoglua, "Quality of honeys influenced by thermal treatment," LWT-Food Science and Technology, vol. 41, no. 8, pp. 1396-1399, 2008.

[10] S. Bogdanov, Harmonized Methods of the International Honey Commission, $\mathrm{CH}$ 3003, Swiss Bee Research Centre, Bern, Switzerland; FAM, Liebefeld, Switzerland, 2002.

[11] C. Sainz-Laín and C. Gómez-Ferreras, Mieles Españolas: Características e Identificación Mediante el Análisis del Polen, MundiPrensa, Madrid, Spain, 2000.
[12] L. Persano-Oddo and S. Bogdanov, "Determination of honey botanical origin: problems and issues," Apidologie, vol. 35, supplement 1, pp. S2-S3, 2004.

[13] A. Gómez-Pajuelo, "Origen botánico de la miel," in Mieles de España y Portugal, pp. 50-56, Montagud, Barcelona, Spain, 2004.

[14] A. C. Soria, M. González, C. De Lorenzo, I. Martínez-Castro, and J. Sanz, "Characterization of artisanal honeys from Madrid (Central Spain) on the basis of their melissopalynological, physicochemical and volatile composition data," Food Chemistry, vol. 85, no. 1, pp. 121-130, 2004.

[15] M. G. Piazza and L. Persano-Oddo, "Bibliographical review of the main European unifloral honeys," Apidologie, vol. 35, supplement 1, pp. S94-S111, 2004.

[16] L. P. Oddo, T. A. Heard, A. Rodríguez-Malaver et al., "Composition and antioxidant activity of Trigona carbonaria honey from Australia," Journal of Medicinal Food, vol. 11, no. 4, pp. 789-794, 2008.

[17] F. Tornuk, S. Karaman, I. Ozturk et al., "Quality characterization of artisanal and retail Turkish blossom honeys: determination of physicochemical, microbiological, bioactive properties and aroma profile," Industrial Crops and Products, vol. 46, pp. 124131, 2013.

[18] BOE 24621, Reglamento de la Denominación de Origen Protegida "Miel de Granada" y de su Consejo Regulador, 2002.

[19] S. Preys, E. Vigneau, G. Mazerolles, V. Cheynier, and D. Bertrand, "Multivariate prototype approach for authentication of food products," Chemometrics and Intelligent Laboratory Systems, vol. 87, no. 2, pp. 200-207, 2007. 

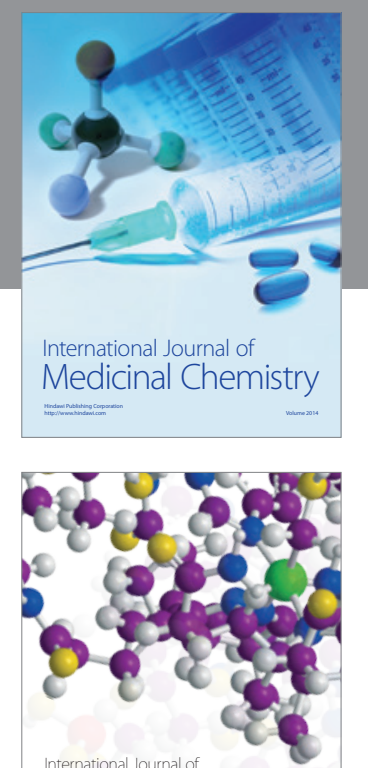

\section{Carbohydrate} Chemistry

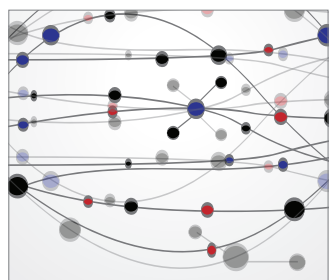

The Scientific World Journal
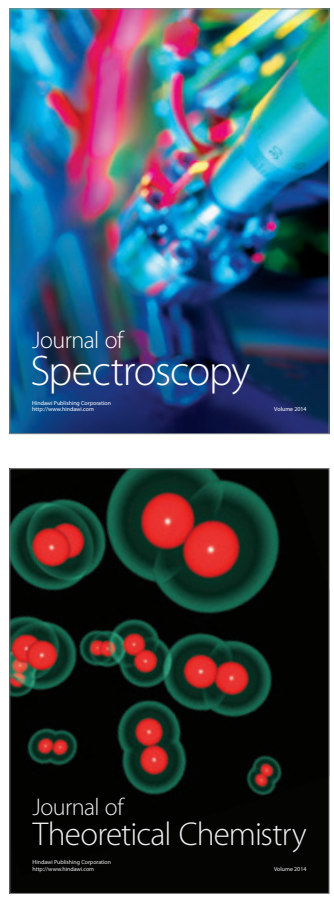
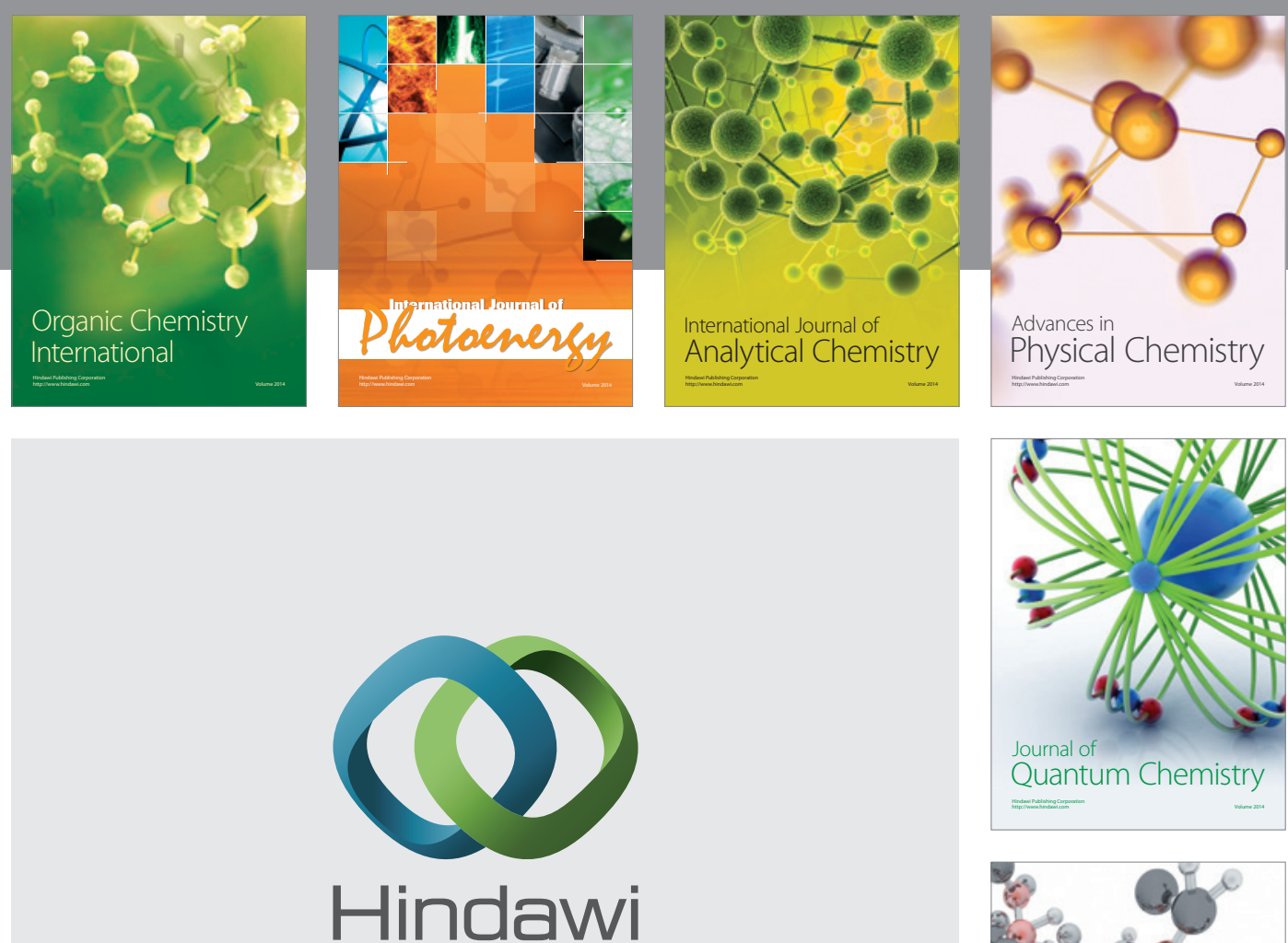

Submit your manuscripts at

http://www.hindawi.com

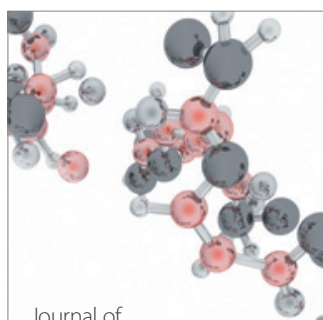

Analytical Methods

in Chemistry

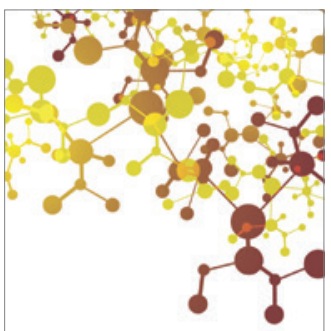

Journal of

Applied Chemistry

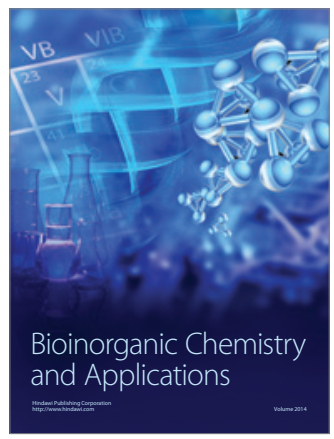

Inorganic Chemistry
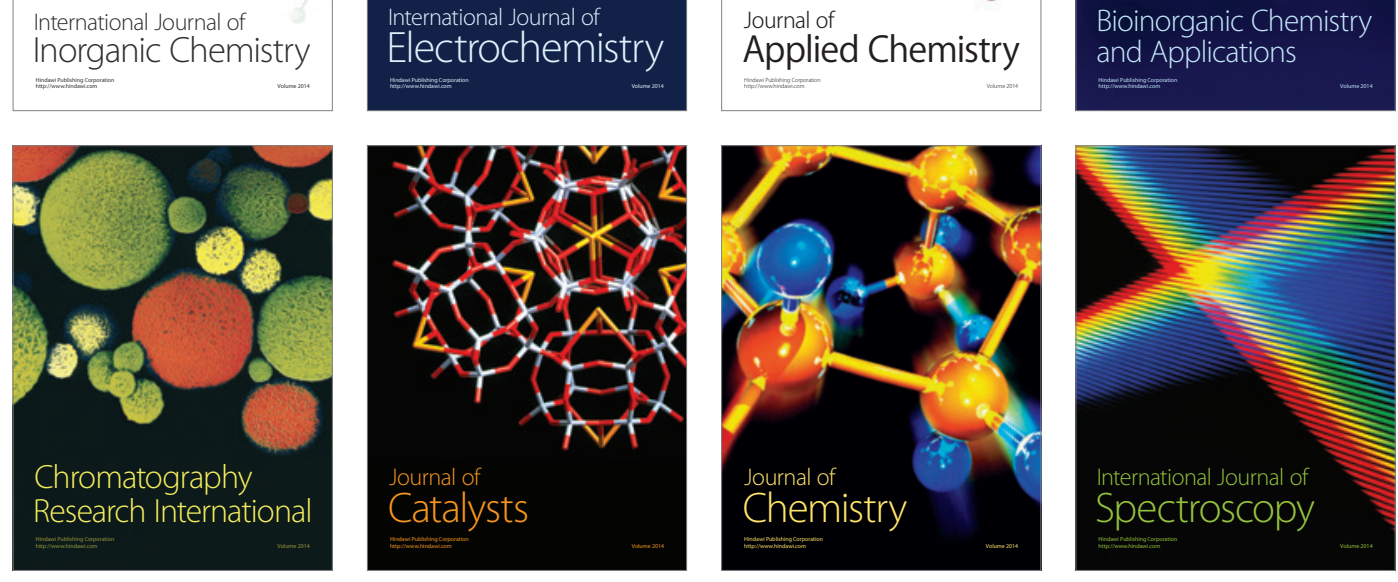